\title{
Effect of ceramic particles on the dynamic strength, deformation and toughness behavior of $42 \mathrm{CrMo} 4$
}

\author{
Kevin Koch $^{1 *}$, Volodymyr Kietov ${ }^{1}$, Sebastian Henschel ${ }^{1}$, and Lutz Krüger ${ }^{1}$ \\ ${ }^{1}$ Institute of Materials Engineering, TU Bergakademie Freiberg, 09599 Freiberg, Germany
}

\begin{abstract}
In this study, the effect of non-metallic inclusions on the material behavior of $42 \mathrm{CrMo} 4$ was investigated. By adding aluminum oxide particles to steel powder, different inclusion contents were simulated. The mechanical and fracture toughness properties were measured under dynamic loading. The damage was examined using the acoustic emissions. With an increasing inclusion content, a decreasing strength, deformability and fracture toughness were observed. The distribution of the inclusions along the surfaces of the prior steel particles lead to small distances between inclusions and favors the initiation of cracks at low stress. The early appearance of material damage was proven by acoustic emissions.
\end{abstract}

\section{Introduction}

It is known that non-metallic inclusions affect the deformability and toughness of materials $[1,2]$. Ductile fracture consists of void nucleation, void growth and void coalescence [3]. Due to their internal notch effect, non-metallic inclusions serve as void nucleation sites. MnS and $\mathrm{Al}_{2} \mathrm{O}_{3}$ are known to be common non-metallic inclusions in steels [4]. The void nucleation rate increases with inclusion content, while void growth rate increases with inclusion size [5]. Void coalescence is affected by the spacing of inclusions [6,7]. Therefore, the existence of inclusion clusters in casting materials is detrimental $[4,8,9]$.

The fracture toughness can be predicted based on characteristics of the material. Hahn and Rosenfield [10] assume that fracture occurs when the crack tip opening displacement is equal to the mean particle distance $\lambda$ of void nucleating particles. It is given by

$$
\lambda=0,554\left(\frac{4 \pi}{3 f}\right)^{\frac{1}{3}} r
$$

where $f$ is the volume content of inclusions an $r$ is the mean particle radius. Therefore, plane strain fracture toughness $K_{\text {Ic }}$ can be estimated by

$$
K_{\mathrm{Ic}}=\sqrt{2 E \sigma_{\mathrm{ys}} \lambda}
$$

*Corresponding author: kevin.koch@iwt.tu-freiberg.de 
where $\sigma_{\mathrm{ys}}$ is the yield stress an $E$ is the Young's modulus. The model has been validated for composites with $\mathrm{Al}_{2} \mathrm{O}_{3}$ reinforcement particle sizes of 5 - $10 \mu \mathrm{m}$ [11]. Eq. (2) may also be used to estimate $\lambda$ from $K_{\text {Ic }}$.

Material damage can be examined by acoustic emissions. Usually the emissions are converted into a voltage signal by a transducer. Based on parameters of the signal such as amplitude, duration and frequency, conclusions on the cause of acoustic emissions can be drawn. This has been studied recently on steel and nodular cast iron [12-14].

The aim of the present study is the experimental determination of strength, deformation and fracture toughness behavior of $42 \mathrm{CrMo} 4$ steel with different ceramic particle contents under dynamic loading. For this purpose, materials with specifically selected particle contents were processed using field assisted sintering technology. These particles correspond to the non-metallic inclusions in a real component. The material damage was examined considering the fracture surfaces and by acoustic emissions analysis.

\section{Materials and Methods}

\subsection{Material}

Specimens were processed by field assisted sintering technology (FAST). Powder of $42 \mathrm{CrMo} 4$ steel with an average particle size of $24.6 \mu \mathrm{m}$ was used as base material. For simulating specific volume contents of non-metallic inclusions, $\mathrm{Al}_{2} \mathrm{O}_{3}$ powder with an average particle size of $5.2 \mu \mathrm{m}$ was added to steel powder. A homogeneous distribution of the components was pursued by using high energy ball milling. The sintering process was carried out in vacuum $\left(1100{ }^{\circ} \mathrm{C}, 5 \mathrm{~min}\right.$ dwell time at $48 \mathrm{MPa}$, uncontrolled cooling). Dense specimens without noticeable porosity were sintered. The samples were subsequently hardened (vacuum, $840{ }^{\circ} \mathrm{C}, 20 \mathrm{~min}$, quenching at 15 bars in $\mathrm{He}$ ) and tempered $\left(450{ }^{\circ} \mathrm{C}, 60\right.$ $\min , \mathrm{N}_{2}$ ). The aim of the heat treatment was to achieve a tempered martensitic structure. Tab. 1 gives an overview of the different volume contents of the simulated inclusions. In addition to the ceramic particles, existing impurities had to be considered. These may have formed through oxidation of metal surfaces during powder treatment and were determined in a microscopic examination, showing an average content of $0.5 \mathrm{vol} \%$. Fig. 1 shows the microstructure of the three different materials (M1 to M3).

Table 1. Overview of simulated inclusion contents.

\begin{tabular}{cccc}
\hline Material & M1 & M2 & M3 \\
\hline Inclusion content $\left(\mathrm{Al}_{2} \mathrm{O}_{3}\right.$ added) [vol\%] & $0.5(0)$ & $2(1.5)$ & $5(4.5)$ \\
\hline
\end{tabular}
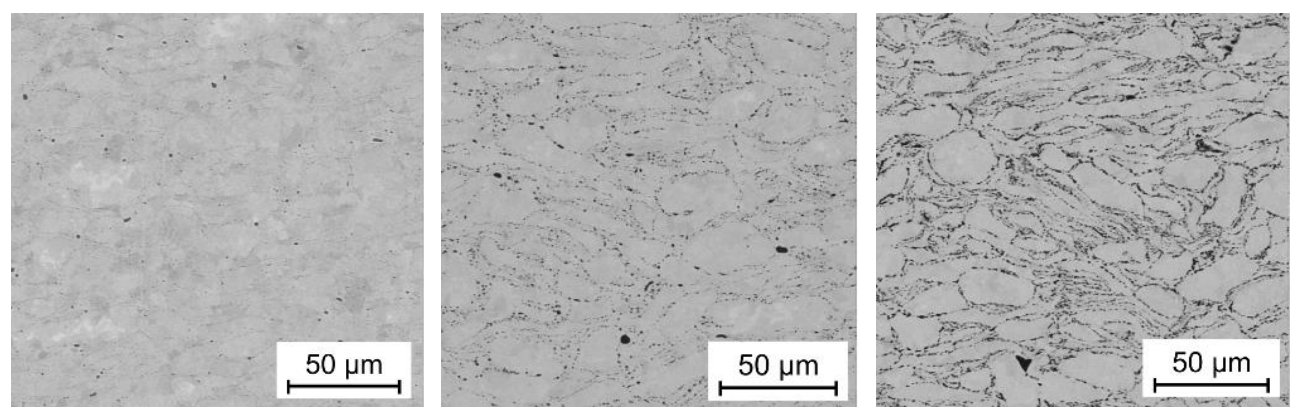

Fig. 1. Microstructure of M1 (left), M2 (center) and M3 (right). 
It shall be noted that the added ceramic particles were located around the former steel particles. With an increasing amount of $\mathrm{Al}_{2} \mathrm{O}_{3}$, the distances between the particles decreased and thus there were hardly any pores between the alumina particles in M3. Within the areas that were occupied by the former steel particles, no alumina particles were observed.

\subsection{Experimental setup}

To investigate the strength and deformation behavior under dynamic loading, tensile tests on samples with a minimum diameter of $3.6 \mathrm{~mm}$ and a gauge length of $10.5 \mathrm{~mm}$ were carried out with an instrumented drop weight testing machine [15]. Thus, ultimate tensile strength and plastic strain at failure were measured at a strain rate of approximately $100 \mathrm{~s}^{-1}$. The force was measured by strain gauges at the elastically-deforming part of the specimen (diameter 7 $\mathrm{mm}$ ). For measuring the strain of the specimen, an optical extensometer was applied, Fig. 2.
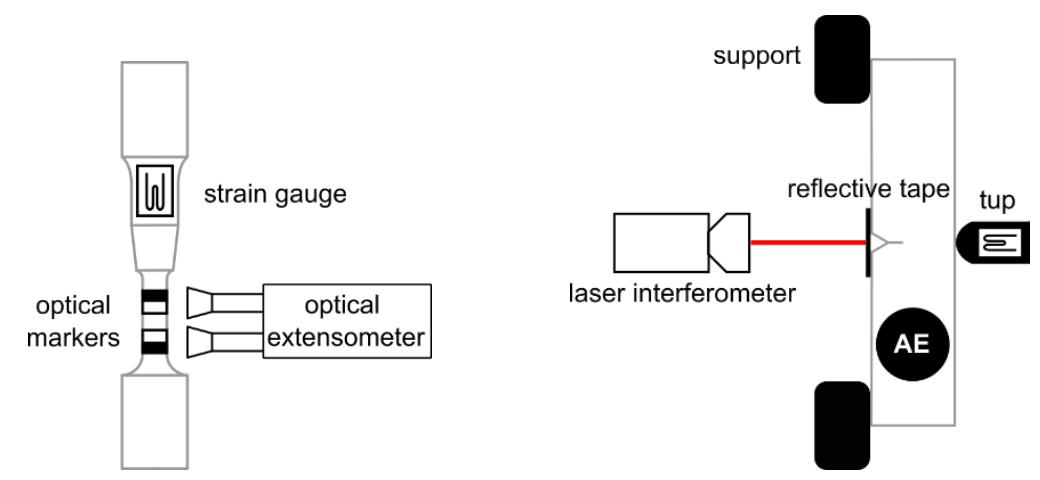

Fig. 2. Setup for dynamic tensile tests (left) and Charpy impact tests (right).

Low-blow Charpy impact tests [16] were performed in an instrumented pendulum testing machine to measure the dynamic fracture toughness. Therefore, notched Charpy specimens with a fatigue crack $(a / W=0,5)$ were used. Fig. 2 shows the experimental setup. An impact velocity of $0.3 \mathrm{~m} / \mathrm{s}$ led to a loading rate of approx. $5 \cdot 10^{4} \mathrm{MPam}^{0,5} \mathrm{~s}^{-1}$. For measuring the force during tests, strain gauges were attached to the tup of the hammer. The displacement as well as the velocity of the specimen in the load line were measured with a laser doppler interferometer. Details can be found in [17].

For measuring the acoustic emissions, a piezoelectric transducer (type Pico, Physical Acoustics Corporation) was mounted on the surface of the specimen. This transducer shows high sensitivity for frequencies of 400 to $600 \mathrm{kHz}$, which corresponds to cleavage fracture [12]. The position is shown in Fig. 2. Additionally, a broadband filter $(10 \mathrm{kHz}-2 \mathrm{MHz})$ and an amplifier $(20 \mathrm{~dB})$ were used. The voltage signal was recorded continuously with a sampling frequency of $2 \mathrm{MHz}$. It was examined in the frequency domain with a Fast Fourier Transform (FFT). Therefore, impact vibrations and material damage could be distinguished to determine the onset of unstable crack growth. Further information is given in $[13,14]$.

\section{Results and discussion}

Dynamic tensile tests were carried out on samples of M1 and M2. Results are shown in Fig. 3 with added data from tests under quasi-static loading on the same material [18]. The strain rate measured while testing was between $90 \mathrm{~s}^{-1}$ and $130 \mathrm{~s}^{-1}$. At quasi-static as well as at dynamic loading rates, hardly any strain hardening and necking of the samples was observed. A small increase in tensile strength as well as a larger increase in strain at failure was observed under dynamic loading. This has already been observed on $42 \mathrm{CrMo} 4$ casting 
material [19]. The added alumina particles led to a slight decrease in tensile strength. However, the decrease of strain at failure was more noticeable. This can be attributed to the high alumina particle content, combined with the arrangement along the boundaries of the former steel particles that lead to small inclusion distances.

The results of the dynamic fracture toughness tests are shown in Fig. 3. All samples showed linear-elastic behavior until fracture. This behavior was also observed in three-point bending tests under quasi-static loading [18]. Only a minor increase in fracture toughness under dynamic loading could be observed for M1 and M2, while it decreases for M3. Furthermore, the dynamic fracture toughness decreases with increasing volume content of alumina particles. However, the decrease is not as significant as the fracture toughness is already at a relatively low level for M1 without adding alumina particles. One reason for the generally low fracture toughness was the presence of the already existing impurities before adding the alumina particles.
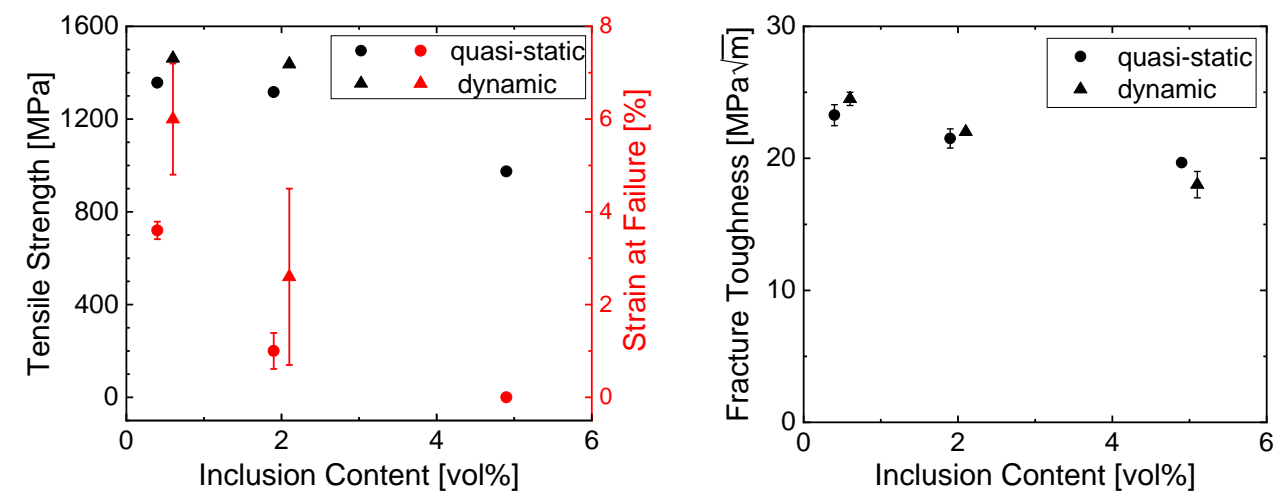

Fig. 3. Results for dynamic tensile tests (left) and Charpy low-blow tests (right). Data points were slightly shifted for better visibility.

The dynamic fracture toughness was predicted by the Hahn-Rosenfield model. First $\lambda$ was estimated by Eq. (1) for each tested inclusion content. Then $K_{\text {Id }}$ was calculated by Eq. (2) with $E=208 \mathrm{GPa}$ and $\sigma_{\mathrm{ys}}=1438 \mathrm{MPa}$. A comparison with results from experiments in Tab. 2 shows that $K_{\text {Id }}$ is overestimated by the model. By rearranging Eq. (2), $\lambda$ was calculated from the experimental $K_{\text {Id. }}$. The resulting adapted $\lambda$ showed to be noticeably smaller than when estimated by Eq. (1). This can be accounted to high inclusion contents and the local inhomogeneous distribution of the inclusions that is not considered by the model. However, the adapted $\lambda$ agreed with the local particle spacing of particles observed in microstructure.

Table 2. Comparison of experimental and theoretical results.

\begin{tabular}{|c|c|c|c|c|}
\hline $\begin{array}{c}\text { Inclusion content } \\
\text { [vol\%] }\end{array}$ & $\begin{array}{c}\lambda \\
{[\mu \mathrm{m}]}\end{array}$ & $\begin{array}{l}\operatorname{model} K_{\text {Id }} \\
{[\mathrm{MPa} \sqrt{\mathrm{m}]}}\end{array}$ & $\begin{array}{c}\text { Experiment } K_{\text {Id }} \\
{[\mathrm{MPa} \sqrt{ }]}\end{array}$ & $\begin{array}{c}\underset{[\mu \mathrm{m}]}{\operatorname{adapted} \lambda} \\
\end{array}$ \\
\hline 0.5 & 2.9 & 41.8 & 24.5 & 1.0 \\
\hline 2 & 1.8 & 33.2 & 22.0 & 0.9 \\
\hline 5 & 1.4 & 28.5 & 18.0 & 0.7 \\
\hline
\end{tabular}

The fracture surfaces showed hardly any deformations with small and flat dimples, Fig. 4. This could be observed for all particle contents. Further investigations showed that the crack propagated along the boundaries of the former steel particles. Additionally, smaller cracks occurred underneath the fracture surface. These may have formed due to the small distances between the non-metallic inclusions, which favored crack initiation at low loads. The fracture surfaces also showed no signs of stable crack growth or crack tip blunting. 

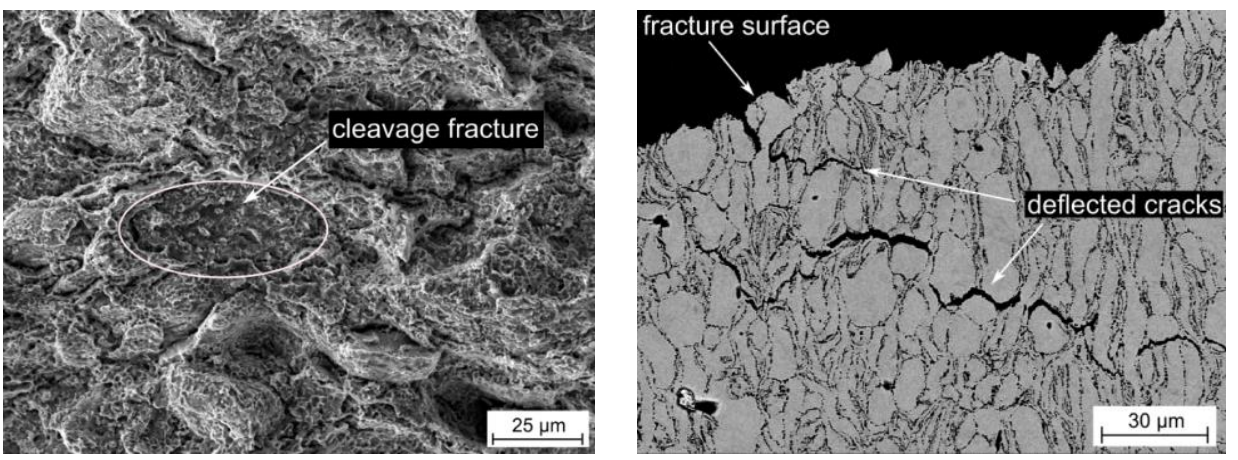

Fig. 4. SEM image: fracture surface of a M3 sample with areas of cleavage fracture (left) and perpendicular to the fracture surface (right).

Fig. 5 shows the force signal and the corresponding AE signal of a Charpy impact test with an impact energy $E_{0}$ of $1 \mathrm{~J}$ for M1. Due to the small impact velocity of about $0.3 \mathrm{~m} / \mathrm{s}$, only negligible inertia effects were present in the force signal. However, the analysis of the AE signal showed an initial pulse which corresponds to vibrations that originated from the hammer impact [13]. The Fast Fourier Transform shows the frequency spectrum of the AE signal. The amplitude is represented by the FFT magnitude. Frequencies below $100 \mathrm{kHz}$ were observed during the impact in all tests as well as small amounts of signals with higher frequency between 0.1 and $0.25 \mathrm{~ms}$. These were attributed to local material damage [13] and showed to be more significant at lower alumina particle contents. The duration of the impact signal until fracture decreased with increasing content of alumina particles.
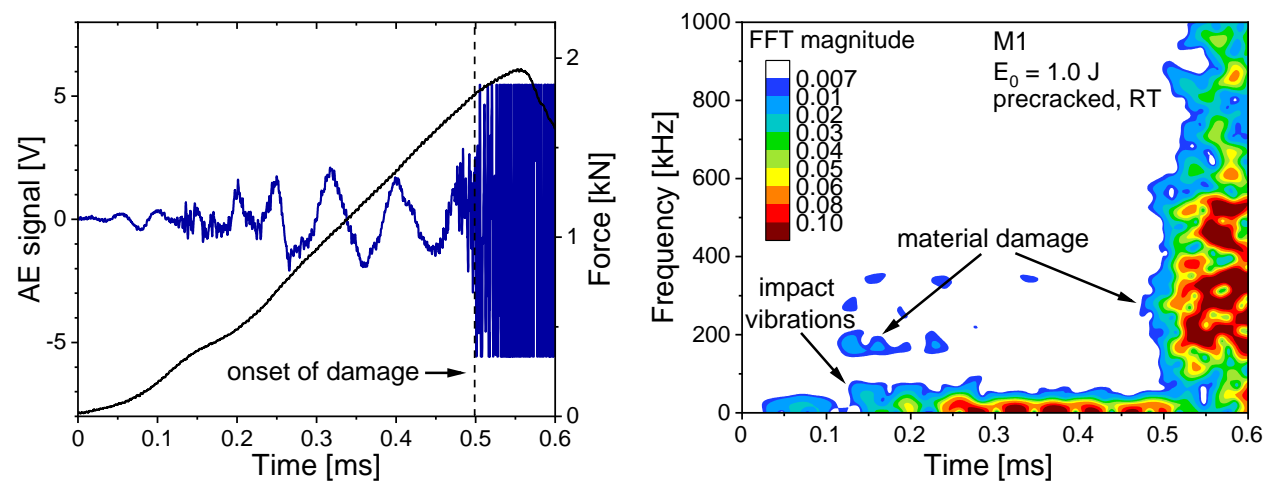

Fig. 5. Charpy low-blow test for M1 at $1 \mathrm{~J}$ impact energy: waveform of the AE signal (left) and spectrogram of the AE signal (right), FFT was performed in windows with a length of 51,2 $\mu$ s [13].

At around $0.48 \mathrm{~ms}$, additional high-amplitude signals were observed. Those can be attributed to material damage $[13,14]$. The AE signals showed frequencies between 200 and $600 \mathrm{kHz}$ which correspond to both, ductile and cleavage fracture. To this point, the force signal still shows linear elastic behavior since damage occurs only locally. This can be observed as the magnitude of the AE signal is relatively low before fracture. The accumulating local damage ultimately leads to global material damage and unstable crack growth. This is indicated by a kink in the force slope as well as a transition in frequency of the AE signal at $0.5 \mathrm{~ms}$. The rapid and significant release of energy lead to AE signals with high magnitude. The amplitude occured to be significantly high, exceeding the measurement range which can lead to a loss of AE signal information for the Fourier transform. However, this part of the AE signal was not crucial for analyzing material damage since fracture already happened at this point. No significant differences were observed when comparing the 
waveforms and frequency spectrums of the tests. This corresponded to the similar fracture toughness behavior.

\section{Conclusions}

Investigations were carried out to measure the effect of alumina particles on the mechanical and fracture toughness properties of sintered $42 \mathrm{CrMo} 4$ powder. The material showed brittle behavior, even without adding alumina particles. By adding more $\mathrm{Al}_{2} \mathrm{O}_{3}$ to the steel powder, a slight decrease in strength and a significant decrease in deformability was observed. The effect on fracture toughness was dominated by the occurrence of non-metallic inclusions. A homogeneous distribution of inclusions was not achieved. Alumina particles were located along the former surfaces of the steel particles. Therefore, crack initiation was favored at low loads. For modeling fracture toughness, the local distribution of inclusions was considered. The AE analysis showed high amounts of signals with high magnitude shortly before fracture due to the onset of unstable crack growth. This could be estimated by analyzing the frequency of the AE signals.

The authors would like to thank the German Research Foundation (DFG) for supporting the investigations in the subproject C05, which are a part of the Collaborative Research Center CRC 920 Project-ID 169148856. The support of Florian Posselt is greatly appreciated.

\section{References}

1. W. M. Garrison jr., N. R. Moody, J. Phys. Chem. Solids, 48 (1987) 11, p. 1035-1074.

2. W. C. Leslie, Trans. Iron Steel Soc. AIME, 2 (1983), p. 1-24.

3. R. D. Thomson, J. W. Hancock, Int. J. Fract., 26 (1984) 2, p. 99-112.

4. S. Henschel et al., Adv. Eng. Mat., 15 (2013) 12, p. 1216-1223.

5. T. B. Cox, J. R. Low jr., Met. Trans., 5 (1974) 6, p. 1457-1470.

6. K.-H. Schwalbe, Eng. Fract. Mech. 9 (1977) 4, p. 795-832.

7. D. Broek, Eng. Fract. Mech., 5 (1973) 1, p. 55-66.

8. S. Henschel, L. Krüger, steel research int. 87 (2016) 1, p. 29-36.

9. S. Henschel, L. Krüger, EPJ Web of Conferences 183, 02001 (2018)

10. G. T. Hahn, A. R. Rosenfield, Metallurgical Transactions A, 6 (1975) 4, p. 653-668.

11. A. Rabiei, L. Vendra, T. Kishi, App. Sci. Man., 39 (2008) 2, p. 294-300.

12. S. Henschel et al., Mat. Sci. Eng. A, 709 (2018), p. 152-159.

13. V. Kietov, S. Henschel, L. Krüger, Eng. Fract, Mech., 188 (2018), p. 58-69.

14. V. Kietov, S. Henschel, L. Krüger, Eng. Fract. Mech., 210 (2019), p. 320-341.

15. ISO 26203-2, Metallic materials - Tensile testing at high strain rates - Part 2: Servohydraulic and other test systems (2011).

16. ISO 26843, Metallic materials - Measurement of fracture toughness at impact loading rates using precracked Charpy-type test pieces (2015).

17. S. Henschel, L. Krüger, Mater. Test., 57 (2015) 10, p. 837-842.

18. K. Koch, V. Kietov, S. Henschel, L. Krüger, In: M. Vormwald (Ed.): 53. Tagung des DVM-Arbeitskreises Bruchmechanik und Bauteilsicherheit. (2021). Berlin: DVM e.V. (DVM-Bericht, 252), to be published.

19. S. Henschel, S. Dudczig, L. Krüger, C. G. Aneziris, Pro. Str. Int., 2 (2016), p. 358-365. 